\title{
The Ability to Provide Clean Water
}

\author{
Haoyuan Jin \\ School of Automation, North China Electric Power University, Baoding 071003, China; \\ 1031868763@qq.com
}

Keywords: Clean water; DPSIR framework; analytic hierarchy process; criteria for evaluation.

\begin{abstract}
The issue of water resources has always been a matter that people pay close attention to. The ability of a country or region to provide clean water represents the state of its water resources. This paper mainly solves the problem of measuring the ability of a region to provide clean water. Using the method proposed in the paper, it can quantify the capacity of providing clean water and can more directly see the difference in water resources among different regions. Based on the DPSIR framework, this paper uses the analytic hierarchy process to calculate the weight distribution of each index and provides an evaluation standard to measure the capacity of providing clean water, which is a good solution to this issue.
\end{abstract}

\section{Introduction}

As the population grows and various problems of water resources become more and more serious, the ability of a country or region to provide clean water has received widespread attention. Will the world's clean water run out? Is it possible to provide clean water for all people? Many similar problems are deeply troubling people. Based on the DPSIR framework, this paper establishes a model to measure the ability of a region to provide clean water, and gives the corresponding evaluation indicators to solve the doubts in people's minds.

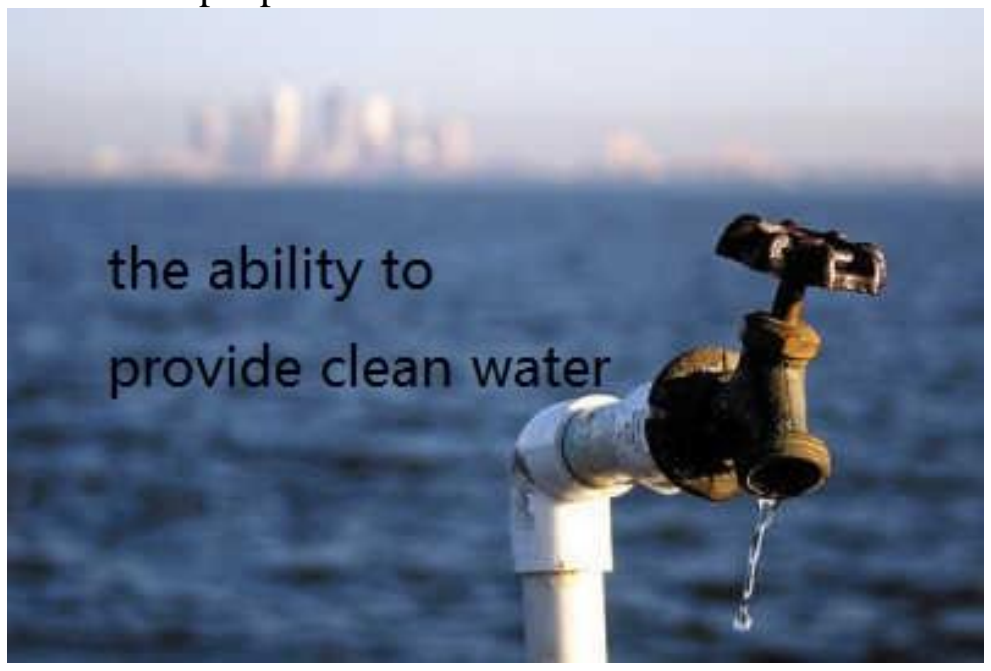

Fig. 1 The ability to provide clean water

\section{The DPSIR framework}

In this section, we based on the DPSIR framework to pinpoint the factors that affect the ability of a region to provide clean water [1].

The so-called DPSIR model refers to the evaluation model which conclude driving force, pressure, state, impact and response five aspects.

Among the five aspects, the driving forces are the potential causes of environmental change, including the long-term development of the society, economy and population.

Pressure is the impact of human activities on the surrounding environment.

State refers to the situation of environment under the influence of pressure. 
Impact means the changes of the health of human beings and social-economic structures caused by the environmental conditions.

Response refers to the policy that the human taken to ease the deterioration of the environment.

Because of its universality, it is widely used in environmental systems.

Considering from the above five aspects, almost all factors that affect the ability to provide clean water are involved. After determining the influencing factors, the next step in evaluating the ability to provide clean water is to determine the weight of each indicator.

\subsection{Applying analytic hierarchy process to determine the weight.}

Indicator weight can reflect the relative importance of different indicators in the evaluation system, which occupies an important position in the evaluation system. The method of determining the index weight is the subjective weighting method and the objective weighting method. In this part, we decide to use the analytic hierarchy process which is a kind of the subjective weighting method to determine the weight.

Analytic Hierarchy Process (AHP) is a decision-making method that decomposes elements that are always related to decision-making into objectives, criteria and indicators, and on this basis, qualitative and quantitative analysis [2].

First, we carefully considered all the possible indicators and divided them into the target layer, the criterion layer and the indicator layer according to AHP. According to the characteristics of economy, society and environment, and according to the principles of maneuverability, timeliness, government order and prominence, this paper selects 18 factors that can characterize the characteristics and utilization status of clean water as specific evaluation indexes. 18 specific evaluation indicators as shown in Table 1:

Table 1 The ability to provide clean water index system based on DPSIR framework

\begin{tabular}{|c|c|c|}
\hline Target layer & Criterion layer & Indicator layer \\
\hline \multirow{18}{*}{$\begin{array}{c}\text { the ability } \\
\text { to provide } \\
\text { clean water evaluation }\end{array}$} & Driving & Total population \\
\hline & force & Natural growth rate \\
\hline & indicators & GDP \\
\hline & & The number of large livestock \\
\hline & State & Per capita GDP \\
\hline & indicators & Per capita water resources \\
\hline & & Surface water resources \\
\hline & & Groundwater resources \\
\hline & & Total water resources \\
\hline & & Effective irrigation area \\
\hline & Pressure & Industrial water \\
\hline & indicators & water for life \\
\hline & & Ecological water \\
\hline & & Total discharge of waste water \\
\hline & Impact & Forest cover rate \\
\hline & indicators & Built green rate \\
\hline & Response & the area of soil and water loss \\
\hline & indicators & Urban sewage treatment capacity \\
\hline
\end{tabular}


From the criterion layer, experts in water resources research and ecological research are invited to assign relative importance to each indicator using the 1-9 scale method (see Table 2) in order to form the judgment matrix and calculate the maximum feature of the vector Value $\lambda \max$ and the eigenvalue of the eigenvector, and after normalization processing, we can calculate and judge the consistency index CI of matrix in light of the formula as follows:

$$
C I=\frac{\lambda_{\max }-n}{n-1}
$$

In the formula: $\mathrm{n}$ is the number of indicators of the corresponding criteria layer (others are the same). According to Table 3, the random consistency index RI can be obtained, then calculate the consistency of the judgment matrix ratio $\mathrm{CR}$

$$
C R=\frac{C I}{R I}
$$

Table 2 1-9 scaling method

\begin{tabular}{|c|c|c|c|c|c|c|}
\hline Altitude & 1 & 3 & 5 & 7 & 9 & 2、4、6、8 \\
\hline \multirow{2}{*}{ meaning } & Equally & Moderate & Obviously & Very & Extremely & median \\
\cline { 2 - 8 } & important & important & important & important & important & \\
\hline
\end{tabular}

Table 3 Random index

\begin{tabular}{|c|c|c|c|c|c|c|c|c|}
\hline $\mathrm{n}$ & 1 & 2 & 3 & 4 & 5 & 6 & 7 & 8 \\
\hline $\mathrm{RI}$ & 0 & 0 & 0.58 & 0.90 & 1.12 & 1.24 & 1.32 & 1.41 \\
\hline
\end{tabular}

When $\mathrm{CR}<0.1$, this paper considers the judgment matrix to be more satisfactory agreement. The greater the $C R$ value, the greater the consistency. When $C R>0.1$, the author believes that the inconsistency of the judgment matrix is unacceptable. The judgment matrix needs to be adjusted until $\mathrm{CR}<0.1$, at which point the judgment matrix conforms to the consistency requirement and the weight assignment is reasonable and effective.

Using Matlab software to calculate $\lambda \max$ and corresponding eigenvalue $\omega$, we can get the consistency ratio $\mathrm{CR}$. If $\mathrm{CR}<0.1$, indicating that the judgment matrix conforms to the consistency requirement and the weight distribution is reasonable.

According to the above steps, we calculate the weight and test the consistency of the stress indicators, status indicators, impact indicators, response indicators and guidance layer in turn, if all the judgment matrices satisfy the consistency requirement, indicating that the weight distribution is reasonable. Ranking all indicators of index layer in order and test the consistency, then obtained the weight distribution in the AHP of each indicator.

\subsection{The criteria for evaluation.}

After calculating the weight distribution of each indicator, the evaluation value can be obtained through a simple sum of the product of the indicators data and weights. The specific evaluation criteria are shown in the following table:

Table 4 Grading standards of the ability to provide clean water

\begin{tabular}{|c|c|c|}
\hline Comprehensive evaluation & grades & The ability \\
\hline$\geqslant 0.75$ & I & excellent \\
\hline$[0.50,0.75)$ & II & good \\
\hline$[0.25,0.50)$ & III & general \\
\hline$<0.25$ & IV & poor \\
\hline
\end{tabular}

According to the interval shown in the table, the ability of a country or region to provide clean water can be measured. 


\section{Summary}

With the increasing prominence of water resources, if we can continuously use of clean water has become a great confusion in people's minds. Against this background, this article provides a way to quantify the ability to provide clean water and to make it more intuitive for people to understand the state of water resources in a region.

\section{References}

[1]. Lin Wang, Chao Zhang. Evaluation of Sustainable Utilization of Water Resources in Weifang Based on "Driving Force-Pressure-State-Influence-Response" Model [J]. Journal of Ocean University of China. Vol. 43(2013) No. 12, p. 75-80.

[2]. Information on: https://baike.so.com/doc/5386070-5622520.html 